\title{
LA POLÍTICA DE LO COMÚN. EXPERIENCIAS Y SABIDURÍAS PARA EL BUEN VIVIR
}

\author{
ASIER MARTÍNEZ DE BRINGAS \\ Universidad de Deusto
}

\begin{abstract}
RESUMEN: Uno de los ejes centrales de este ensayo es el de enfatizar la importancia de lo Común para la producción, reproducción y desarrollo de la vida en un sentido amplio y complejo. No hay que olvidar que lo Común es la clave para comprender la producción económica, social y ecológica, así como la forma en que se produce toda forma de riqueza vital. La privatización de lo Común implica una limitación de su potencia, de su productividad, de su esencia; un cercenamiento de su riqueza intrínseca. La producción de lo Común excede constantemente todo marco de medida y de control. Lo Común nos enseña que la construcción de la individualidad como tal es una fantasía sino se entiende desde los vínculos que política y emocionalmente nos coagulan estructuralmente a los grupos, a la comunidad. Esta potencia y posibilidad de lo Común para la vida va a ser una de las principales pretensiones de este ensayo. Desde ahí, la praxis y experiencia de los pueblos indígenas resulta fundamental para entender, orientar y aplicar este proyecto de lo Común.
\end{abstract}

PALABRAS CLAVE: lo común, derechos humanos, relacional, libertad, Buen Vivir.

\section{The Policy of the Commons. Experience and Wisdous from "Buen Vivir"}

ABSTRACT: One of the central themes of this essay is to emphasize the importance of the Common for the production, reproduction and development of life in a large and complex sense. Do not forget that the Common is the key to understanding the economic, social and ecological production, as well as how vital that all forms of wealth occurs. The privatization of the Common implies a limitation of their power, their productivity, their essence; curtailment of its inherent wealth. The production of the common framework consistently exceeds all measurement and control. The Common teaches us that the construction of individuality as such is a fantasy but it is understood from the links coagulate us politically and emotionally structurally groups, community. This power and possibility of the common life is going to be one of the main scope of this essay. From there, the practice and experience of indigenous peoples is essential to understand, guide and implement this project of the ordinary.

KEY WORDS: Common, human rights, relational, freedom, Buen Vivir.

\section{ConteXtualización}

Hay importantes razones que motivan la emergencia de una categoría tan arcaica como la de lo Común, ubicándola en el centro de la discusión política de los nuevos movimientos sociales y de las nuevas reivindicaciones de derechos. Una de esas razones es la desvitalización y el desfonde de la idea de revolución como medio para la transformación de las estructuras de poder. Otra es el irrefrenable proceso de mercantilización de la vida y de los procesos a ella vinculados, entendido todo ello en un sentido holístico: biodiversidad, recursos naturales y humanos; afectos y emociones; bienes comunes culturales entendidos como prácticas sociales y relacionales en forma de hábitos, tradiciones, lenguas; valores y activos intangibles e inmateriales, y un largo etc. Una última 
razón, importante para las pretensiones de este ensayo, sería la conexión de lo Común con los derechos a partir del concepto de Buen Vivir. El Buen Vivir, en cuanto categoría fundacional del modo de vida indígena, evidencia la importancia de proceder mediante una praxis relacional en la manera de entender los derechos ${ }^{1}$, lo que hace difícil poder separar lo individual de lo colectivo en la forma de entender la producción social y la vida.

Uno de los ejes centrales de este ensayo es el de enfatizar la importancia de lo Común para la producción, reproducción y desarrollo de la vida en un sentido amplio y complejo. No hay que olvidar que lo Común es la clave para comprender la producción económica, social y ecológica, así como la forma en que se produce toda forma de riqueza vital. La privatización de lo Común implica una limitación de su potencia, de su productividad, de su esencia; un cercenamiento de su riqueza intrínseca. Privatizar lo Común supone en sí mismo una contradicción de difícil resolución ${ }^{2}$. Es como querer reducir lo colectivo a lo individual. La producción de lo Común, paradójicamente, excede constantemente todo marco de medida y de control. Lo Común nos enseña que la construcción de la individualidad como tal es una fantasía ${ }^{3}$ sino se entiende desde los vínculos que política y emocionalmente nos coagulan estructuralmente a los grupos, a la comunidad. Lo Común no se decreta desde ninguna exterioridad, no es el resultado de meros agregados, sino que depende de un proceso social que tiene su propia lógica ${ }^{4}$. Esta potencia y posibilidad de lo Común para la vida va a ser una de las principales pretensiones de este ensayo. Desde ahí, la praxis y experiencia de los pueblos indígenas resulta fundamental para entender, orientar y aplicar este proyecto de lo Común.

Ubicados en este contexto narrativo es interesante clarificar qué vamos a entender por lo Común para poder traducirlo en un proyecto político y jurídico coherente. Dicho proyecto pasa por refundar el concepto de lo Común otorgando una centralidad interpretativa a los derechos colectivos en cuanto instrumentos para la construcción y protección del mismo.

Procederemos para ello, fijando, en primer lugar, el valor y sentido político de lo Común, entendiendo éste como un proyecto fraguado a lo largo de la historia por convergencia de energías y esfuerzos comunitarios. Desde ahí, su

1 Esta práctica relacional hay que entenderla como práctica sistémica y circular que pasa por una comprensión interdependiente e inescindible de los vínculos de la persona con lo socio-comunitario; de lo socio-comunitario con la persona; y de este sistema personal-comunitario con la naturaleza y la biodiversidad que nos circunscribe. Esto es, para los pueblos indígenas no es posible individualizarse, entender el concepto de identidad, sino es relacionalmente, vinculados con el grupo y la comunidad; así como con las conexiones emocionales que está implica: el buen vivir.

2 Negri, A., Commonwealth. El proyecto de una revolución del común, Madrid, Akal, 2011, pp. 290 y ss.

3 En el sentido de Hernando, A., La fantasía de la individualidad. Sobre la construcción sociohistórica del sujeto moderno, Katz, Madrid, 2012, pp. 111-145.

4 Este es el sentido de la magna obra de LaVal, CH. y Dardot, P., Común. Ensayo sobre la revolución en el siglo XXI, Barcelona, Gedisa, 2015. 
sentido político tiene un carácter transformador y enriquecedor de la realidad; resulta ser una alternativa para encauzar el discurso de los derechos. En segundo lugar, realizaremos un análisis de algunas de las confusiones históricas que se han ido construyendo y proponiendo para entender lo Común, con la finalidad de evidenciar dónde se ubican los principales conflictos en torno a esta problemática. En tercer lugar, profundizaremos en lo que consideramos desviaciones o incomprensiones del discurso liberal para interpretar, recibir y valorar el programa de lo Común. En cuarto lugar, estableceremos una conexión estructural entre el Buen Vivir indígena (en cuanto categoría fundante de su propia cosmovisión) y el proyecto de lo Común, con el fin de fijar paralelismos a partir de las prácticas indígenas de vida y de derechos, de enorme fecundidad y proyección para la construcción de lo Común. En quinto lugar, haremos una recapitulación de lo que consideramos los principales aprendizajes que se desprenden de un proyecto de lo Común, enseñanzas fundamentales para diseñar un proyecto de sostenibilidad y auto-regulación en nuestro proyecto global e interdependiente de vida.

\section{Sentido POlítico de lo Común}

La pregunta por lo Común lleva inextricablemente asociada el cuestionamiento sobre las condiciones de posibilidad de la «acción común» y sus efectos; esto es, el abordaje de los problemas que plantea la acción colectiva cuando se utilizan recursos de uso común ${ }^{5}$. Partimos, para el abordaje de esta cuestión, de la tradicional dicotomía establecida por los economistas clásicos entre bienes privados y bienes públicos, entre propiedad pública y privada, a partir de la originaria distincion establecida entre mercado y Estado. Los bienes públicos y privados determinan su naturaleza a partir de criterios como la rivalidad y la exclusividad. Los bienes públicos (no rivales y no exclusivos), puestos en escena por intervención del Estado en algún escenario de la vida, pretenden suplir las deficiencias del mercado, las fallas del sistema, allí donde éste no pueda alcanzar a regular el desarrollo de alguna actividad; es decir, aquello que por limitaciones sistémicas no puede ser bien privado. Ahora bien, si se combinan los criterios de rivalidad y exclusividad de forma cruzada, se produce la aparición de otros bienes, híbridos o mixtos, diferentes de los públicos y privados: nos referimos a «bienes de club» (exclusivos y no rivales), y «bienes comunes» 6 . Será el premio nobel de economía, Elinor Ostrom, quien establecerá esta nueva

5 Zubero, I., «De los comunales a los commons: la peripecia histórica de una práctica ancestral cargada de futuro", en Documentación Social. Revista de Estudios sociales y sociología aplicada, $\mathrm{n}^{\circ} 165$, abril-junio 2012, pp. 12 y ss. Una interesante exposición histórica del proceso de creación y desarrollo de los comunes puede encontrarse en Hess, $\mathrm{CH}_{\mathrm{H}}$, "Is There any Thing new Under de Sun? A discussion and survey of studies on new commons and the internet», disponible en: http//dlc.dlib.indiana.edu/archive/00000512.

6 Laval, С 
propuesta y, sobre todo, la acepción de «bien común». Los bienes comunes serán, en palabras de Ostrom, bienes cuyo acceso no se puede restringir, salvo que se establezcan reglas de uso; lo que llamó «fondos de recursos comunes». Su uso no supone elegir entre propiedad pública o privada, sino que los bienes comunes podrán ser gestionados de modo duradero y eficaz a través de la acción colectiva y autorganizada ${ }^{7}$.

A diferencia de los bienes privados y públicos, la apropiación, construcción, mantenimiento y sostenibilidad de los «bienes comunes» exige una «acción política de apropiación» por parte de los ciudadanos y la comunidad que funciona como una garantía de protección frente a otros; esto es, los excluye de su apropiación y utilización para evitar así su disolución, su desaparición ${ }^{8}$. Esta es la naturaleza política de la cualidad «rivalidad» exhibida en toda su intensidad por la naturaleza del «bien común».

Aunque la aportación de Ostrom es de gran interés para fraguar y profundizar una teoría de la acción colectiva y del desarrollo institucional en torno a los «bienes comunes», no es el sentido de esta acepción en la que nos vamos a fundamentar en este ensayo, sino la de lo Común en singular, que tiene un sentido político diferente, cualitativamente distinto, más amplio, primigeniamente acuñado por Hart y Negri en Multitud ${ }^{9}$. Lo Común dará nombre a objetos de naturaleza muy diversa y plural de los que se ocupa la actividad colectiva de las personas, pero se trata más de un principio que anima toda esta actividad socio-comunitaria y que preside la construcción de formas de autogobierno ${ }^{10}$. El gran aporte de Ostrom residió - frente a los postulados de la economía clásica de mediados del siglo xx-, en llamar la atención sobre el estrecho vínculo que existe entre normatividad y reciprocidad; en enfatizar la importancia de la gestión democrática y la participación activa en la producción de ciertos recursos, esto es: vínculos sociales fuertes y normas de reciprocidad para su gestión. Ostrom nos expone un mapa interesante para el diseño de un sistema institucional otro que permita la organización de la gestión común, más allá de la bipolaridad Estado-mercado; siembra el terreno y remueve sus entrañas para ubicar el sentido y posibilidades de la acción colectiva y de sus condiciones políticas. Su marco teórico, sin embargo, se queda estrecho puesto que no tiene en cuenta el contexto económico global en que se producen e interactúan los bienes comunes. Frente a Ostrosm, una teoría de lo Común tiene que hacerse cargo de las relaciones de poder (en todos sus niveles), de los procesos de explotación y de dominación sistémicas que caracterizan nuestros mundos de la vida, en definitiva, de la conflictividad política de lo real.

7 Oostrom, E., Governing the Commons. The Evolution of Institutions for Collective Action, Cambridge, Cambridge University Press, 1990, pp. 45 y ss.

8 Harvey, D., Ciudades rebeldes. Del derecho de la ciudad a la revolución urbana, Madrid, Akal, 2013, pp. 115 y ss.

9 Multitud: guerra y democracia en la era del imperio, Barcelona, Debate, 2004, p. 8 y ss.

10 Este es el sentido general de la obra de LaVal y Dardot: op. cit., p. 25. 
Lo Común, más que una propiedad de los bienes centrada en criterios de rivalidad-exclusión, refiere más a una manera de entender lo institucional acompañado por una arquitectura de reglas y normas que permitan al individuo y la comunidad compartir propiedad(es) y recursos, lejos de la espontaneidad con la que se quiere describir el funcionamiento de ciertos bienes económicos (públicos, privados, comunes) ${ }^{11}$. No hay nada de espontáneo en lo Común, sino más bien una intensa voluntad política de configuración y estructuración. Lo Común en cuanto principio de estructuración social implica una co-actividad desde la que se define políticamente su núcleo esencial: esa coactividad no es otra que la lógica inescindible del derecho-deber hacia lo Común; de la lógica del deber funcionando conjuntamente con el reconocimiento; de la deuda y del don tan propios y necesarios para todo actuar común. Este es, también, el sentido de derechos humanos que preconizamos: aquél en los que el deber es parte de su núcleo esencial.

La dimensión política de lo Común se integra necesariamente en la lucha por otras formas de vida y existencia no estrictamente capitalistas. La práctica política, como expresa Harvey, será bifronte: i) por un lado, para impulsar al Estado a esforzarse en el suministro de bienes públicos; ii) por otro, ensamblando cuadros de auto-organizacion dispuestos a apropiarse y usar lo Común ${ }^{12}$. Si se adelgaza la acción estatal para la protección y promoción de los bienes públicos administrados, irrumpe, como posibilidad la auto-organización para gestionar lo Común, quebrando la rígida dicotomía mercado-Estado en la que parecía haberse encerrado toda forma de comprensión de un bien. Lo Común no implica una estrategia de confrontación con el Estado; más bien es siempre una estrategia complementaria para una gestión institucional más lúcida y eficaz. Este es precisamente el sentido de los derechos colectivos: límites de lo colectivo frente al poder.

La importancia política de lo Común radica en la incapacidad de los bienes y derechos de propiedad privada para satisfacer los intereses comunes; en una limitación radical e intrínseca de cierta manera de comprender los derechos individuales y propietarios como instrumentos para dar medida de intereses y necesidades sociales que desborden ese ámbito de protección. En una economía política donde el centro de gravedad ya no reposa en la producción de mercancías materiales, sino en las relaciones sociales, la importancia de lo Común revela nuevas líneas creativas y exploratorias para los derechos humanos. El discurso de los derechos debe hacerse cargo de un cambio sustantivo que se ha producido en el interior de la globalización y que afecta a su capacidad para ofrecerse como instrumento de garantía de la dignidad de personas y grupos. Nos referimos a que la dicotomía clásica entre sujeto productor y objeto

11 Íbid, pp. 165 y ss.; Howe, C. W., Natural Resources Economics, Issues, Analysis and Policy, New York, Wiley \& Sounds, 1979, pp. 72 y ss.; Ciriacy-Wantrup, S. V. y Bishop, R., "Common Property as a Concept in Natural Resources Policy», en Natural Resources Journal, $\mathrm{n}^{\circ} 15$, pp. 713-727.

12 Harvey, D., op. cit., pp. 135-136. 
producido ya no funciona ni resulta eficaz. Tanto productor como producto son sujetos (de derechos): los seres humanos producen y son producidos ${ }^{13}$, lo que plantea un reto radical desde el punto de vista de los derechos y que tiene una conexión estructural con lo Común. La tensión que expone en toda su intensidad y profundidad lo Común es la que se produce entre la propiedad (privada o pública) y lo inapropiable. El sentido político último de lo Común tiene que ver con lo inapropiable, con aquello que no es susceptible de ser encerrado en una institución como la propiedad, puesto que no es en sí mismo un bien, sino un principio de estructuración de la vida.

La importancia y el debate sobre lo Común establecen cuatro líneas prioritarias de trabajo de la que debe hacerse cargo una teoría crítica centrada en lo colectivo. En primer lugar, redefinir las relaciones con la naturaleza, cuestión que forma parte de la esencia de los derechos colectivos indígenas a través de términos como Sumak Kawsay (Buen Vivir) y Suma Qamaña (Convivir Bien) ${ }^{14}$. Se trata de conceptos fundadores para los pueblos indígenas que tienen que ser repensados y reapropiados por la tradición liberal, y que pasan por transitar de una consideración de explotación y utilización productiva de la Naturaleza y sus recursos, al respecto de la misma como fuente de vida y posibilidad. Es todo lo que tiene que ver con una dimensión preventiva de los derechos humanos teniendo en cuenta las generaciones futuras. Ello pasa por no aceptar, como modo exclusivo de gestión y apropiación, la propiedad privada de los recursos naturales; pasa por la introducción de nociones como la de costos ecológicos en la racionalidad económica, evitando el destructivo concepto de externalidades para justificar procesos de explotación de recursos naturales; pasa por la introducción de mecanismos de gestión común y control colectivo; pasa por la ampliación del concepto de reservas de la biodiversidad; y por la promoción de prácticas de agricultura orgánica, campesina, indígena, o agro-ecológicas, y un largo etc. En segundo lugar, reorientar la producción de la base de la vida, priorizando, la lógica de las utilidades y las productividades, sobre las del valor de cambio. Ello implica redescubrir el territorio. El territorio como espacio de actividad económica, cultural, política y espiritual. De ahí que conceptos como soberanía alimentaria y energética sean sometidos a un principio superior como es el de reconducir la satisfacción de las necesidades a la dimensión del territorio ${ }^{15}$. En tercer lugar, reorganizar la vida colectiva hacia la generalización de la democracia en las relaciones sociales y en las instituciones. Lo Común como nueva práctica de organización interna de lo político, de las instituciones e, incluso, de apropiación y utilización de los derechos individuales. Se trata de revisar nuestras prácticas de derechos iluminados desde el sentido de lo Común. De nuevo, la experiencia indígena en sus formas de organización social y

13 Negri, A., op. cit., p. 150.

14 Albo, X., «Suma Qamaña = Convivir Bien. ¿Cómo medirlo?», en Diálogos, año 1, nº 0, 2010, pp. 54-64.

15 Houtart, F., El bien común de la humanidad, Quito, Instituto de Altos Estudios Nacionales, 2013, p. 56 y ss. 
política sirve como reflejo de lo Común. En cuarto lugar, ubicar la interculturalidad como base para el arraigue y difusión de lo Común ${ }^{16}$.

\section{Confusión, EQuívocos y faLACIAS ENTORNO A LO COMÚN}

La confusión sobre lo Común descansa en una idea flotante, como ya ha sido sugerida, propia de espacios arraigados en una comprensión convencional de la economía, empeñada en identificar lo Común con acceso libre a los bienes; o ausencia de propiedad en sentido lato, confundiendo el problema de lo Común, con el concepto de propiedad común. Este es un tema clave en relación a los derechos territoriales de los pueblos indígenas. La problemática tiene que ver con el acceso a los recursos naturales en territorialidad indígena, que, además, tienen una naturaleza colectiva. Esto es, la territorialidad indígena funge como un Común en la que territorialidad no puede entenderse sin la comprensión cosmovisional con la que los pueblos la habitan, lo que hace que los recursos naturales sea una cualidad inescindible del territorio. Un eje importante del conflicto consiste en procesar y articular cómo se sustancia la consulta a los pueblos indígenas cuando la presencia de empresas o terceros ajenos al territorio quieren acceder a la explotación de los recursos naturales (gas, petróleo, carbón, oro, etc.), sitos en territorio indígena; o cómo se establece un régimen de colaboración y reparto de beneficios en torno a la explotación de esos bienes, que, inicialmente, son de propiedad comunal indígena; o el valor normativo que se otorga al consentimiento previo libre e informado indígena frente las consultas del Estado, etc. Es decir, los problemas de llegar a acuerdos sobre el reconocimiento fáctico y normativo (como establece el Derecho Internacional) de los derechos territoriales indígenas - lo Común-, de sus propias formas de auto-organización y disposición sobre los recursos naturales, sin confundir nunca estos derechos territoriales indígenas, con bienes privados, bienes públicos o simples bienes comunes. El sentido Común de los derechos indígenas, de lo Común indígena, se fundamenta en la autodeterminación comunitaria. Esta da sustento a toda debate sobre la consulta en territorio indígena. La autodeterminación indígena no es más que una institución que permite, en última instancia, una gestión de lo Común de acuerdo a reglas y consensos en distintos niveles: con el Estado y con terceros sitos en territorio indígena. Por tanto, es falso el debate que se viene planteando en América Latina entre consulta del Estado vs. Consentimiento indígena. El fondo del asunto es la autodeterminación indígena puesto que este principio normativo es el que mejor expresa lo Común indígena ${ }^{17}$.

16 Martínez de Bringas, A., «Derechos humanos y diversidad(es) cultural(es). Los retos de la interculturalidad» en Derechos y Libertades, año 16, nº 26, pp. 109-144.

17 Cf. Martínez de Bringas, A., «El Derecho a la consulta de los pueblos indígenas. Naturaleza, elementos y procedimiento para su aplicación en el Estado», en RVAP, IVAP, n ${ }^{\circ}$ 93, agosto 2012, pp. 127-149. 
Una segunda línea de confusión tiene naturaleza historiográfica, esto es, olvidar y hacer tabla rasa sobre el papel fundamental que lo Común ha jugado a lo largo de la historia de cara a la delimitación de formas de poder y regímenes de propiedad ${ }^{18}$. La lógica de la Modernidad ha procedido produciendo una fractura insalvable entre lo Político y el Derecho; políticamente se decide que lo Común no forma parte de los sistemas jurídicos organizados (de ahí deriva la dificultad para entender el Pluralismo Jurídico al que aboca el pensamiento indígena), considerando lo Común, a partir de esta separación falaz, como una patología arcaica. El principio de soberanía hace que el Estado se convierta en poseedor de la voluntad común; en sustituir la voluntad común por voluntad pública. Ello es más claro en el diagrama colonial, sobre todo si se tiene en cuenta que la construcción de los Estados postcoloniales se ha realizado sobre la base del genocidio y aniquilación sistemática de los pueblos indígenas.

Una tercera línea de confusión consiste en identificar la tragedia de los comunes ${ }^{19}$ con la tragedia del individualismo metodológico (sentido patrimonialista de los derechos), vinculado éste a una falsa concepción sobre el egoísmo y el papel del Estado en Adam Smith ${ }^{20}$, lo que se ha traducido, por inversión, en la "tragedia de los anticomunes» ${ }^{21}$. Hardin cree que la lógica inherente de los comunes genera una tragedia descomunal. El problema de Hardin es que llama común a una amalgama de bienes y situaciones muy diferentes, no distinguiendo lo común de bienes que, por ejemplo, no tienen propiedad (agua, aire, etc.), pero pueden ser apropiados. Le preocupa sobre manera, desde unos zapatos malthusianos, la explotación sin restricciones de bienes. Además, desvirtúa el valor cualitativo de lo Común cuando proclama que «La libertad de los recursos comunes resulta la ruina para todos»: estos sólo serían justificables en condiciones de baja densidad poblacional ${ }^{22}$. Para Hardin, la alternativa a lo Común no necesita ser "perfectamente justa» para ser preferible ${ }^{23}$. Con estas expresiones se encuentra inhabilitado para comprender la relación de

18 Cf. Un profundo estudio de todas estas cuestiones puede verse en LAVAL y DARDOT: op. cit., pp. 15-68; 263-518.

19 Cf. En el sentido del artículo fundante de la polémica: Hardin, G., «La tragedia de los comunes» «La tragedia de los comunes» en Gaceta Ecológica, $\mathrm{n}^{\circ}$ 37, Instituto Nacional de Ecología, México, 1995, en http://www.ine.gob.mx/. Cf. En un sentido crítico, KLINK, A., «¿La tragedia de la propiedad común o la tragedia de la mala interpretación en la economía?», Agricultura y Sociedad, n 61, octubre-diciembre, 1991, pp. 157-181; «Hardin, Ostrom y los recursos de propiedad común: un desencuentro inevitable y necesario», en ZuBERo (Coordinación), Documentación Social, $n^{\circ} 165,2012$, pp. 37-51.

20 HaRdin, G., op. cit.

21 Heller. M., "The tragedy of antiCommons. Property in the transition from Marx to the Markets», Harvard Law Review, vol. 111, n 3, enero de 1998, pp. 621-688.

22 HaRdin, G., op. cit. p. 11.

23 (...) nuestro sistema legal de propiedad privada más herencia es injusto, pero nos quedamos con él porque no estamos convencidos, por el momento, de que alguien haya inventado un sistema mejor. La alternativa de los recursos comunes es demasiado aterradora para contemplarse. La injusticia es preferible a la ruina total», Ibid. 
complementariedad que hay entre una política de lo Común y la lógica de la autolimitación necesaria para hacer sostenible la vida en nuestra globalización. No entiende que lo Común, en su dimensión relacional con lo individual, encierra un compromiso con la autocontención y con prácticas sostenibles de vida. Hardin está constantemente tensionado por la dicotomía bien privado-bien público, Estado-mercado, privatización-nacionalización; desde ahí es incapaz de intuir una tercera vía de escape, sostenible a la vez que efectiva, a esta feroz dicotomía: la que permite la gestión de lo Común.

Frente a Hardin, la verdadera «tragedia de los Comunes» reside en su desaparición, cosificación e instrumentalización por parte del juego combinado de mercado, intereses privados y Estado. La despolitización de lo Común reclama ubicar en el centro del debate la tensión dialéctica existente entra la propiedad (privada-pública-bien común) y la legitimidad (de lo Común) ${ }^{24}$.

Otro ámbito de confusión alude a la relación de lo Común con los problemas de cercamiento, protección y delimitación de los mismos. A gran escala, un cierto cercamiento de la biodiversidad y de las culturas para su protección es necesario. Este es el fondo de preocupación común de los derechos territoriales indígenas. Éstos, basados en una concepción fundamentada en la sostenibilidad y el Buen Vivir (como más tarde se verá), más que en la dimensión productiva del territorio y la tierra, demandan garantías de protección para hacer sostenibles a estas culturas: sus formas de vida individual y colectiva. El problema de fondo es la mercantilización de lo Común, en sus diferentes formas de expresión. Aunque se considere que el cercamiento de lo Común sigue la misma estrategia de protección que los sistemas de propiedad privada en un marco capitalista, es necesario, a modo de protección, el cercamiento de los mismos en un contexto general de escasez, evitando, de esta manera, el acceso depredatorio de las mayorías a lo Común. Nada garantiza que los individuos o corporaciones privadas, que saquean sistemáticamente la riqueza común, actúen en paralelo colectivamente para asegurar la reproducción de esa misma riqueza. El individuo-corporación, que actúan exclusivamente por intereses privados a corto plazo, tiende a destruir sistemáticamente las condiciones de su propia reproducción ${ }^{25}$. Este es quizá, entonces, uno de los principales problemas-equívocos para la reproducción de lo Común. La política es la «esfera de actividad de un común que sólo puede ser contencioso", como ha expresado acertadamente Rancière ${ }^{26}$. La conflictividad con lo Común no tiene que ver con las formas de gestión de un bien o una cosa, más bien reposa en una actividad

24 Mattei, H., Bienes Comunes. Un manifiesto, Madrid, Trotta, 2013, p. 16.

25 Como dice Harvey: qué incentivo tienen los individuos para obedecer las reglas «del buen comportamiento de mercado» cuando los beneficios derivados de hacerlo son bajos y el «rendimiento de la ilegalidad, la depredación, el robo es muy alto aún teniendo en cuenta las enormes multas que podrían caer sobre ellos por ese mal comportamiento?» en HaRveY, D., "Apropiación privada y riqueza común», en Diecisiete contradicciones y el fin del capitalismo, Quito, Instituto de Altos Estudios Nacionales del Ecuador, 2014, p. 72.

26 Rancière, J., Disagreement, Universty of Minnesota Press, Minneapolis, 1999, p. 14. 
que se construye en y con el conflicto. Se podría concluir, en torno a este equívoco, que el problema no es lo Común, sino el haz de relaciones entre quienes lo producen y mejoran, y quienes se apropian de él para su beneficio privado.

Otro importante equívoco tiene que ver con la tendencia a separar y disgregar sistémicamente cuestiones que van inextricablemente unidas, como la reproducción social, el género y lo Común. Es necesario volver a recombinar y vincular estas dimensiones separadas por la división social del trabajo tan propia del modo de producción capitalista. La distancia insalvable abierta entre la producción y la reproducción, así como el irrefrenable consumo con el que actuamos, nos lleva a ignorar los costos sociales y ambientales, así como el fatídico destino al que abocamos otras comunidades y seres humanos, dado el interdependiente vínculo existente entre nuestras acciones (producción) y los contextos y efectos (reproducción) que las mismas producen. La producción de nuestra forma de vida implica, inevitablemente, la muerte de otras formas de vida. Es necesario superar el velo de la irresponsabilidad sobre nuestras acciones y los efectos que las mismas producen sobre lo Común en una escala global; transitar el «gap» de responsabilidad entre lo que se produce, reproduce y consume ${ }^{27}$.

Otro de los equívocos en relación a lo Común reposa en una consideración rígida del Derecho que se expresa en una concepción del legislador como operador omnipotente en su manera de entender y tratar la propiedad en su relación con lo Común. Ello lleva implícito una concepción jerárquica del concepto de soberanía, así como una consideración estrecha de las fuentes del derecho ceñidas en su validez sólo al ámbito rígido de las fronteras. Se trata del cierre de lo Común a la demarcación y posibilidad que oferta el binomio propiedad privada y Estado. Implica cancelar lo Común en su dimensión ecológico-colectiva, transitando de lo cualitativo colectivo (territorio, autonomía y jurisdicción indígena) a lo cuantitativo individual, tan propio de una consideración patrimonial de los derechos. En lo Común sólo existe una relación cualitativa: no tenemos, sino que somos partícipes de lo Común; lo importante es determinar en qué consiste la exigencia de la práctica de lo Común. Se trata de «ser» más que «tener» ${ }^{28}$; poner el énfasis en la importancia del estar juntos, de lo holístico, de la pertenencia, del saber social y ecológico, frente a una lógica puramente economicista. La separación sujeto-objeto, humanidad-naturaleza, tiene sentido desde una cosmovisión del ser, no del tener. Ello se opone frontalmente a una consideración del Pluralismo Jurídico y de lo Común, tal y como es comprendida y formulada por los pueblos indígenas ${ }^{29}$.

27 Vide, Federici, S., «Women, Land Struggles and the Reconstruction of the Commons» en Working USA: The Journal of Labour and Society, 14, 2011, pp. 41-56; «Feminism and the Politics of the Commons» en www.thecommoner.org (enero 2015)

28 Mattei, H., op. cit., p. 45.

29 MaRTínez DE BRINGAS, A., "Los sistemas normativos indígenas en el marco del pluralismo jurídico. Un análisis desde los derechos indígenas» en Revista de Derecho Político, $\mathrm{n}^{\circ} 86$, 2013, pp. 411-444. 


\section{La desviación Liberal EN LA COMPRENSIÓN DE LO COMÚN}

Hay una cierta tensión fundacional en el pensamiento liberal, de la mano de Adam Smith y Hayek, que nos inquieta y que constituye el punto de partida de este epígrafe. No se trata tanto de una contradicción en el pensamiento liberal, como la sugerida por Macpherson ${ }^{30}$. Hablamos más bien de tensión irresoluble que habita en el propio corazón de la idea de «libertad»y, por tanto, fundamenta y da sentido a toda una concepción ideológica del liberalismo orientada a denostar la idea y la propuesta de lo Común. Esa tensión tiene que ver con el carácter inescindible y trenzado que existe entre libertad y sometimiento. No hay proyecto de libertad en el que no anide, en el corazón de sus intenciones, propuestas complementarias de sometimiento. Como dice Harvey: «cualquier lucha por la libertad debe estar dispuesta a afrontar desde el principio a quién se prepara para someter» ${ }^{31}$.

En este sentido, el precio de la conservación de las libertades conquistadas es una continua tensión y vigilancia para evitar el regreso de lo superado; el retorno de formas antiguas de sometimiento desde un localizado concepto de verdad. Desde esta tensión fundamental que encierra la totalidad sistémica libertad-sometimiento, se van instaurando las bases en la Modernidad para excluir cualquier fundamento para lo Común adherido a una concepción de libertad amplia, abierta y elástica. Lo Común es — para cierta concepción liberal de la libertad- la polaridad, la propuesta a someter y restringir si queremos que el verdadero valor «libertad» prevalezca.

Adam Smith desarrolla, en la Riqueza de las Naciones, un concepto de «libertad natural» que le permite entender el mercado y la división social del trabajo como productos no intencionales, no dependientes de la voluntad humana. Desde ahí considera que lo más recomendable es dejar la economía y el mercado al libre desarrollo de sus libertades; ello resulta más efectivo que cualquier intento bien intencionado de orientar la economía. La acción natural de miles de hombres que pretenden mejorar su condición neutraliza los errores y despropósitos de algunos, incluso del propio gobierno, de la misma manera que cualquier pulsión o tendencia egoísta es armonizada por el propio mercado a la manera de una mano invisible ${ }^{32}$. El efecto principal de la Riqueza de las Naciones fue, por tanto, el establecimiento de una poderosa justificación económica para la búsqueda irrestricta del interés individual, de la mano del concepto de «libertad natural» ${ }^{33}$. Pero todo ello escondía, desde el paradigma de la libertad, una poderosa idea de sometimiento. La dimensión no intencional del mercado escamoteaba una intensa intencionalidad orientada al sometimiento y exclusión de lo Común. El hecho de que los vicios privados promoviesen — de

30 Teoría política del individualismo posesivo. De Hobbes a Locke, Madrid, Trotta, 2005.

31 HaRveY, D., «Libertad y somentimiento», op. cit., p. 201.

32 Sмгтн, А., La riqueza de las naciones, p. 402.

33 Hirschman, A., Las pasiones y los intereses, México, FCE, 1978, pp. 116 y ss.; Tendencias autosubversivas. Ensayos, México, FCE, 1996, pp. 251-282. 
manera natural— los beneficios públicos pone en escena una clara concepción de lo Común que exige inhibición y sometimiento para que la lógica de la libertad natural funcione. La lógica del sometimiento de Smith deriva de su idea de libertad fundamentada en una serie de valores fundamentales, como son: la prudencia, el cumplimiento de la justicia, las leyes de mercado y la humildad frente a los designios de la Providencia ${ }^{34}$. Desde la dialéctica libertad-sometimiento, Smith desarrolla toda una ética social orientada a evitar toda intervención en el mercado e impedir el socavamiento de las condiciones normativas fundantes de éste, como son la propiedad privada y los contratos; la búsqueda del beneficio individual y el respeto a las leyes de justicia.

De manera paralela, Hayek levanta toda su teoría moral sobre los fundamentos establecidos por Smith. Comparte con él la idea de que la moralidad vigente en una sociedad, sus objetivaciones e instituciones fundamentales que dan sentido al orden social son productos humanos espontáneos, no intencionados. En ellos no interviene la razón, sino una suerte de evolución cultural autorregulada. Para Hayek la libertad del individuo propietario es el motor y fundamento de toda moral. La libertad es un concepto negativo que en sus trascendentalidad describe el estado de las cosas a las que todo individuo aspira e intenta aproximarse, pero que nunca puede llegar a cumplir en su plenitud ${ }^{35}$. A su vez, para Hayek, la moral es la principal condición de posibilidad del orden social; lo que constituye en sí mismo este orden ${ }^{36}$. La moral que hace posible la sociedad que tenemos es la moral vigente; una moral encarnada en instituciones de orden extenso que obligan al individuo y sin las que éste no podría reproducir su vida, desarrollarse, vivir. Normas básicas de esta moralidad serían para Hayek: la propiedad privada, el respeto a los contratos, al intercambio, al comercio, a la competencia y el beneficio ${ }^{37}$. Por ello, los efectos de destrucción de la naturaleza no son para él más que meras externalidades del mercado. Para Hayek, esta moralidad no es un producto de la razón, sino de la evolución cultural en los que la tradición y el aprendizaje han cumplido un papel fundamental. Como él expresa, se trata de un «entre» el instinto y la razón ${ }^{38}$. Una selección evolutiva, el de esta moral fundamental, en la que sólo sobreviven los más capaces. Se trata, por tanto, de una nueva versión de los productos no intencionados (como en Smith con su mano invisible) que rebasa todo cálculo y razón, todo interés particular y juicio moral. Es un orden extenso bajo la forma de sociedad capitalista ${ }^{39}$. Sin embargo, este concepto de libertad funciona como un principio máximo de sometimiento a las personas que no piensan igual, que no forman parte de esa moral ni de ese orden extenso, que no tienen las suficientes capacidades

34 SмIтн, A., op. cit., p. 612.

35 HАYек, F., La fatal arrogancia. Los errores del socialismo, Madrid, Unión Editorial, 1990, p. 132.

36 La constitución de la libertad, Madrid, Unión Editorial, 1991, p. 20.

37 La fatal arrogancia, op. cit., pp. 42s, 115, 123.

38 Íbid. p. 42.

39 Íbid., pp. 110 y ss. 
para sobrevivir en un marco de evolución cultural determinado. La dialéctica libertad-sometimiento se expresa en Hayek con toda su crudeza a través de dos ideas: i) la totalización del mercado; ii) la dimensión sistémica de lo social, lo que supone que el sujeto, la persona, de-saparece de su pensamiento. Para él no existe lo social-reproductivo, lo Común como algo valioso; tan solo infinitas acciones de individuos que constituyen algo que llamamos sociedad. El bien común se reduce al «orden abstracto del conjunto» hecho posible por las «reglas de conducta justa». Lo común es, por tanto, el medio que facilita la persecución de una gran variedad de «intenciones individuales» ${ }^{40}$. En cuanto alumbrador de la racionalidad neoliberal Hayek sintetiza el par libertad-sometimiento a partir de la necesidad de cambiar al hombre mismo. El hombre es un inadaptado crónico que debe ser objeto de constante readaptación, de radical transformación en la manera que presenta su vida y destino. No es, por tanto, admisible el constante conflicto que se produce entre la herencia social y la forma en que los hombres deben ganarse la vida. Si no hay simbiosis e interdependencia entre herencia social y economía, el desorden se institucionaliza. Para ello hay que modular y someter las libertades personales ${ }^{41}$.

La tensión entre libertad y sometimiento queda densamente remarcada en el pensamiento de Polanyi al afirmar que el Reino de la libertad reside, en última instancia, en los intereses de clase y ciertos privilegios que sólo se pueden mantener como tales demarcando el territorio que ha de ser sometido para lograr la sostenibilidad y buen orden de ese Reinado. Cuando alguien está seguro y acomodado en su «libertad» se resiste, por principio, a cualquier restricción en sus acciones que impliquen mermas en «esa libertad». Polanyi enuncia una nueva versión de esta tensión dialéctica entre libertad-sometimiento al expresar: «la libertad ¿es una palabra vacía, una tentación destinada a destruir al hombre y sus obras, o bien el hombre puede reafirmar su libertad frente a este conocimiento y esforzarse por ponerla en práctica en la sociedad sin caer en el ilusionismo moral? ${ }^{42}$. De lo afirmado se desprende que la libertad depende de la negación de la realidad social (en su dimensión productiva y reproductiva), y esa negación de la realidad pasa por la negación de lo Común y su sometimiento.

En tensión crítica con esta argumentación - Smith-Hayek- Hinkelammert establece que las llamadas «fuerzas de autorregulación» del mercado no existen. Lo que más bien se da es una determinada autorregulación de mercados particulares, pero no del mercado en su conjunto. El resultado de ello es una estrategia global incompatible con el hecho de que el mundo ha llegado a ser global; esto es, una negación, una vez más, de la importancia de lo Común, de su lógica necesaria para la viabilidad y sostenibilidad de lo global. De manera

40 HaYek, F., Derecho, legislación y libertad. El espejismo de la justicia social, vol. 2, Madrid, Unión Editorial, p. 6 y ss.

41 Cf. Al respecto Laval, C. y Darpot, P., La nueva razón del mundo. Ensayo sobre la sociedad neoliberal, Barcelona, Gedisa, 2013, pp. 87 y ss.

42 Polanyi, K., La gran transformación. Crítica del Liberalismo económico, Madrid, La Piqueta, 1997, pp. 400-403. 
violenta la globalización somete lo Común a las máximas del mercado y la privatización, cosificando la Naturaleza y la biodiversidad a ella vinculada. Para Hinkelammert, una expresión clara del diagrama libertad-sometimiento que venimos sosteniendo viene dada por la crisis de la deuda, que ha tenido la virtud de hacer cargar sus consecuencias más dramáticas y lesivas sobre lo Común, exonerando de responsabilidad a sus productores principales ${ }^{43}$.

De manera complementaria y secuencial Foucault establece en Seguridad, Territorio, Población que la libertad no es otra cosa que el correlato de la introducción de dispositivos de seguridad ${ }^{44}$. La seguridad sólo funciona a cambio de que se sacrifique e hipoteque algo tan importante como la libertad: la libertad de circulación, de movimiento, de desplazamiento de personas, mercancías y capitales. El «liberalismo» para Foucault se justifica por el papel jugado por la libertad en el arte liberal de gobernar: libertad producida por el arte de gobernar. De ahí que el binomio libertad-seguridad determine los procedimientos de control y las formas de intervención estatal. Ahí radica, precisamente, la paradoja del liberalismo y el origen de la «crisis de gubernamentalidad» ${ }^{45}$. El peligro es «el correlato psicológico y cultural interno del liberalismo. No hay liberalismo sin cultura del peligro ${ }^{46}$.

43 Hinkelammert, F., «La rebelión de los límites, la crisis de la deuda, el vaciamiento de la democracia y el genocidio económico social» en Coraggio, J. L. y Laville, L. J., Reinventar la izquierda en el siglo XXI. Hacia un diálogo Norte-Sur, Buenos Aires, Universidad Nacional de General Sarmiento, 2014, pp. 207-220.

44 Foucault, M., Seguridad, Territorio, Población, Madrid, Akal, 2008, pp. 61 y ss. En el curso ofertado en el Colegio de Francia en el periodo 1977-1978 se produce un desplazamiento epistémico en la obra de Foucault. Tras el estudio de la disciplina de los cuerpos, toca ahora el estudio de la regulación de las poblaciones en cuanto correlato del poder y objeto del saber (población en cuanto «masa global afectada por procesos de conjunto que son propios de la vida, como el nacimiento, la muerte, la reproducción, la enfermedad, etc.» en Hay que defender la sociedad, Madrid, Akal, 2003, pp. 216 y ss.). Ello le llevó a poner de relieve el concepto de "gobierno" impulsado por la irrupción de una nueva racionalidad en el arte de gobernar: gobernar menos, pero con eficacia máxima. Para ello Foucault establece una diferencia paradigmática y fundamental entre dispositivos disciplinarios y dispositivos de seguridad: políticas de salud, de higiene pública o medicina social orientadas a disminuir la mortalidad infantil, prevenir epidemias, disminuir pandemias, intervenir en las condiciones de vida para modificarlas — como la alimentación, vivienda, sostenibilidad ambiental, urbanización, deterioro medioambiental, etc. De manera sintética diremos que los dispositivos disciplinarios se aplican sobre la corporalidad de los individuos (prisión, educación, sanidad), mientras que los dispositivos de seguridad se aplican sobre la población, esto es, sobre un cuerpo colectivo, sobre lo Común. Los dispositivos disciplinarios son centrípetos, mientras que la seguridad es centrífuga. En última instancia la disciplina lo reglamenta y regula todo; sin embargo, para la seguridad, un cierto nivel de permisividad es importante; diríamos que es condición de posibilidad para su funcionamiento e implantación. La seguridad debe admitir el funcionamiento de la libertad, promocionarla, para que la seguridad sea efectiva en el long term. La seguridad ni impide, ni establece lo que es obligatorio: regula elementos de la realidad a partir de valores como la libertad. (pp. 13-60).

45 Nacimiento de la Biopolítica, Madrid, Akal, 2012, clase del 24 de enero, pp. 59-80.

46 Íbid., p. 75. 
En consonancia con ello, el liberalismo implicaba una comprensión de la libertad individual que demandaba el desarrollo de toda una estructura autorregulada del gobierno empeñada en poner límites a la arbitrariedad del poder estatal; a la vez que permitía que los individuos pudiesen regular su propia conducta, expandir y limitar su régimen de libertades, siempre que se obedezcan las reglas de mercado ${ }^{47}$. De nuevo estamos ante otra expresión de la dialéctica libertad-sometimiento. A fines del siglo XVIII irrumpe como una exigencia incontestable que la gubernamentalidad debía auto-limitarse, sin que, pese a ello, el gobierno quedase paralizado; y sin socavar ese lugar de verdad cuyo ejemplo privilegiado es el mercado ${ }^{48}$. La gubernamentalidad implica que la libertad no es un fin en sí mismo, sino un medio. Mediante el ejercicio de la libertad el poder estatal se plantea la autodisciplina de poblaciones, comunidades e individuos, asegurando el conformismo y la obediencia a las instituciones que la promocionan y permiten (esa juntura ya conocida de política, economía y derecho). La población, lo Común, queda estatuida y reglamentada como fuerza productiva a partir de la mirada y comprensión de los mercantilistas. Lo Común, en cuanto principio de riqueza que exigía reglamentación disciplinaria, es una de las preocupaciones fundantes del mercantilismo ${ }^{49}$.

De esta manera la libertad queda incorporada, integrada como un medio más en el proceso de mercantilización. Foucault se interroga sobre la naturaleza de la economía política liberal tratando de ubicar el papel y el estatuto que corresponde al Derecho público en este empeño ${ }^{50}$. Desde ahí plantea no la desaparición del poder político, sino la limitación jurídica de una manera de ejercer el poder político; esto es, un desplazamiento en el centro de gravedad del Derecho público, permitiendo dar expansión y salida al par dialéctico libertad-sometimiento que venimos exponiendo. En síntesis, resulta imposible pensar la economía política - la libertad de mercado- sin plantear al mismo tiempo el problema del Derecho público. En este proceso, cada individuo tiende a una cierta interiorización del dominio y la disciplina de sí mismo, lo que implicaba que las concepciones imperantes de «libertad» quedaban arraigadas y en inescindible vínculo con relaciones y códigos sociales derivados de la lógica del intercambio mercantil; esto es, en conexión con la propiedad privada y los derechos individuales en un sentido patrimonial. Desde ahí quedaba fijado lo que se entendía por libertad y su contracara: todo lo que implicaba y reclamaba sometimiento. Como síntesis, con Polanyi y Foucault, la violencia y

47 Íbid, p. 29. Foucault insiste que es necesario entender la palabra liberalismo en sentido muy amplio: i) como aceptación del principio de limitación del gobierno; ii) como práctica: determinando cuál es el principio de limitación gubernamental y dónde están sus límites; iii) como solución consistente en limitar al máximo las formas y ámbitos de la acción de gobierno; iv) como organización de métodos de transacción aptos para definir la limitación de las práctica gubernamentales: constitución, parlamento; opinión, prensa; comisiones, investigaciones. Foucault, Nacimiento de la Biopolítica, Madrid, Akal, 2012, p. 34.

48 Íbid. p. 48.

49 Seguridad, Territorio población, op. cit., p. 79.

50 Íbid., p. 50. 
dominación del Estado están orientadas a sostener las libertades de mercado; y las libertades del capital, descansan, en última instancia, sobre la falta de libertad de los otros; también y ante todo, sobre la regulación y el sometimiento de lo Común.

Harvey critica, en este mismo sentido, la perspectiva de Sen en Desarrollo y Libertad, al proponer que el sistema de mercado, adecuadamente regulado y gestionado, es una manera justa y eficiente de satisfacer las carencias y necesidades humanas, pudiendo promover la liberación de las mismas de forma libre. Ello lo afirma, sin embargo, desde una comprensión de la realidad idealizada, carente de contradicción y de conflictos de clase, obviando, de esta manera, la tensa relación existente entre libertad y sometimiento. La libertad de unos es la contracara del sometimiento de otros ${ }^{51}$, del sometimiento de lo Común.

En refuerzo de la tesis que aquí venimos sosteniendo apelaríamos, en última instancia, a la tesis del riesgo elaborada por Hirchsman en el sugerente ensayo Retóricas de la intransigencia ${ }^{52}$. De manera sintética, la tesis del riesgo es aquella que establece que una reforma materializada y consolidada puede peligrar por la existencia de una nueva ola reformista que se apoye y se subrogue sobre la anterior trascendiéndola, subsumiéndola, descomponiéndola. El peligro se cierne y proyecta siempre sobre logros anteriores consolidados. Ello complementa y da fundamento a la dialéctica inescindible que venimos planteando entre libertad - sometimiento. El arraigo y consecución de la libertad, exige, como condición para su sostenibilidad, la paralización de todo proyecto o reforma posterior que implique la fragmentación de las bases establecidas. Todo proyecto de mejora o perfeccionamiento supone un atentado riesgoso contra la libertad, y por extensión, contra la democracia. Toda acción de progreso puede poner en peligro cualquier expresión o forma social consolidada que haya servido para vivir hasta ese momento. La libertad puede implicar la limitación y sometimiento de todo movimiento que pueda socavar su estabilidad y arraigo. En este mismo sentido, las instituciones del Estado benefactor, fundamentados en un ethos de solidaridad, pueden implicar un enorme riesgo para el mantenimiento de la tradición liberal. La tesis del riesgo anuncia que en la medida que sean más sólidos los valores liberales, cuanto más contundentemente una sociedad esté aferrada a la idea de libertad, más fértil será el terreno para proyectar el peligro sobre otros valores complementarios de la misma, como la igualdad y la solidaridad. En paralelo con esta argumentación, lo Común implica toda una situación de riesgo para el valor libertad por toda la plétora de valores que expone e implica: solidaridad, diferencia, comunitariedad, colectividad, interculturalidad, etc. La libertad implicaría un sometimiento de las fuerzas emergentes y proyectivas que lo Común reclama para arraigarse y ser sostenible.

51 Harvey, D., «Libertad y sometimiento», op. cit., pp. 205-207.

52 Hirchsman, A., Retóricas de la intransigencia, México, FCE, 1991, pp. 97-150. 


\section{LA CONCEPCIÓN INDÍGENA DEL BUEN VIVIR: HACIA UNA FUNDAMENTO PARA LO COMÚN}

El objetivo de este epígrafe es incrementar los posibles fundamentos para una cultura y una lógica de lo Común. Para ello desplegaremos una mirada pedagógica, orientada al aprendizaje desde otras experiencias y prácticas. La cosmovisión indígena del Buen Vivir, en cuanto experiencia fundadora y vital para los pueblos indígenas, nos servirá como guía para el establecimiento de criterios que nos orienten hacia una Política de lo Común. Los retos cosmovisionales que desde hace tiempo afrontan, enfrentan y confrontan los pueblos indígenas tienen que ver con los excesos de vida (social, productiva, reproductiva, económica y ecológica) que el Norte proyecta y hace soportar sobre el Sur, con especial intensidad en los territorios indígenas. Estos excesos dan forma a nuevas expresiones de colonialismo ecológico para entender y asentar renovadas formas de dependencia entre el Norte y el Sur.

Vamos a proceder en este epígrafe a través del establecimiento de una serie de ideas-fuerza que permitan una comprensión simplificada y pedagógica del complejo término «Buen Vivir indígena». Estas ideas-fuerza funcionarán, a su vez, como criterios críticos para revisar ciertas prácticas occidentales de proceder, descabalgadas de proyectos políticos centrados en el despliegue de un proyecto de lo Común, como podrían ser el decrecimiento o el postdesarrollismo ${ }^{53}$; o lo que otros autores vienen llamando "cultura de la autocontención y el reequilibrio»"

Como preámbulo a todo nuestro desarrollo consideraremos el Buen Vivir indígena ${ }^{55}$ como un paradigma normativo para la ordenación social, económica y ecológica ${ }^{56}$. El Buen Vivir propone una fractura cultural centrada

53 El decrecimiento es una corriente de pensamiento económico, social y político orientado a una disminución regulada de la producción económica con el fin de establecer nuevas relaciones de equilibrio entre el ser humano y la naturaleza. Cf. En este sentido AA.VV., "Decrecimiento sostenible», Revista de Ecología Política, n 38, junio 2008; TAIBO, C., En defensa del decrecimiento, Madrid, Catarata, 2009; Latouche, S., La apuesta por el decrecimiento, Barcelona, Icaria, 2008; EscobAR, A., «De la crítica al desarrollismo al pensamiento sobre la economía: pluriverso y pensamiento relacional» en CoREGGIo y LAVILLE (organizadores), op. cit., pp. 191-206; Escobar, A., «El “postdesarrollo” como concepto y práctica social» en Daniel Mato (coord.), Políticas de economía, ambiente y sociedad en tiempos de globalización, Caracas, Facultad de Ciencias Económicas y Sociales, Universidad Central de Venezuela, pp. 17-31; Gudynas, E., «El postdesarrollo como crítica y el buen vivir como alternativa» en Delgado Ramos, G., Buena Vida, Buen Vivir: imaginarios alternativos para el bien común de la humanidad, México, CEIICH, UNAM, 2014, pp. 61-95.

54 Reichmman, J., Autoconstrucción. La transformación cultural que necesitamos, Madrid, Catarata, 2015, pp. 131 y ss.

55 Aosta, A., El Buen Vivir. Sumak Kawsay, una oportunidad para imaginar otros mundo, Icaria, Barcelona, 2013; «El buen vivir como alternativa al desarrollo. Reflexiones desde la periferia de la periferia», en CoREgGio y LAville (organizadores), op. cit., pp. 299-312.

56 Recuperaremos estas triple dimensión en las conclusiones de este trabajo. Pero ya queremos llamar la atención sobre una teoría crítica de lo Común centrada, precisamente, en esta triple perspectiva: la económica, lo socio-productiva y la ecológica. Perspectiva muy cercana a la sugerida por Polanyi en la gran transformación y el sustento del hombre. 
en la crítica de la mercantilización generalizada, del productivismo irrefrenable y del desarrollismo tal y como viene siendo implementado desde el Norte.

Una primera idea fuerza vendría dada por la relación estructural que existe entre el Buen Vivir y el postdesarrollo. Desde ahí, el Buen Vivir indígena se enuncia como una crítica furibunda a las "prácticas de mal desarrollo». Éstas serían aquellas que ignoran, subsumiéndolas como parte incidental y externalidades necesarias del proceso productivo, los costes naturales y sociales; que parten de un falso paradigma en el que el planeta es considerado como un todo inagotable, inextinguible; que establecen una dramática prioridad del valor de cambio - prácticas de intercambio mercantil— sobre el valor de uso y la utilidad intrínseca de la Naturaleza y los recursos naturales; que, en última instancia, identifican las dinámicas de desarrollo con las tasas de ganancia mercantiles.

El anclaje Buen Vivir-postdesarrollo nos lleva, necesariamente, a repensar y a fundamentar las categorías de plurinacionalidad e interculturalidad ${ }^{57}$, centrales en el pensamiento indígena. Las prácticas del Buen Vivir indígenas proponen como fondo paradigmático para el desarrollo del mismo la Plurinacionalidad. Ello implica: una nueva institucionalidad en el marco del Estado (formas indígenas de organización, gobierno y participación comunitaria); una nueva legalidad (Pluralismo jurídico); una nueva concepción de la territorialidad, y no la propia del Estado-nación balizada por fronteras; la necesidad de adaptar el Estado-nación a la territorialidad de los pueblos indígenas y la incrustación trasversal de la territorialidad en el Estado (autonomía asimétrica; prácticas de autogobierno; modelos propios de desarrollo en la consideración de la territorialidad); la irrupción de nuevas subjetividades (reconocer la potencia de lo colectivo y los derechos a ello asociado).

Buen Vivir e interculturalidad también presentan un maridaje de interdependencia. El Buen Vivir apunta a formas de democracia intercultural. Ello implica la existencia de diferentes formas de deliberación democrática tan propio de las prácticas indígenas de construcción política; implica, también, diferentes criterios para dar forma a la representación democrática (la occidental junto con la indígena); el reconocimiento de derechos colectivos indígenas y de nuevos derechos fundamentales asociados a este nuevo paradigma de post-desarrollo llamado Buen Vivir: agua, territorio, soberanía alimentaria, recursos naturales, biodiversidad, consentimiento previo, libre e informado, etc.; y, finalmente, la educación intercultural en condiciones de reciprocidad cultural. Sin embargo, no pueden exponerse las bondades del Buen Vivir sin un ejercicio de autocrítica levantado sobre dos puntos sensibles que la interculturalidad indígena evidencia: por un lado, los déficits democráticos de

57 Santos, B., Sociología jurídica crítica. Para un nuevo sentido común en el derecho, Madrid, Trotta, 2009; El milenio huérfano. Ensayos para una nueva cultura política, Madrid, Trotta, 2005. 
ciertas formas de organización y deliberación indígena hacia el interior de los procesos comunitarias; por otro lado, el notable y problemático proceso de discriminación de la mujer indígena en el interior de sus comunidades ${ }^{58}$. Estamos ante el problemático y basto conflicto de la traducción intercultural de derechos ${ }^{59}$.

Una segunda idea fuerza tiene que ver con la relación Buen Vivir y Naturaleza. La redefinición de las relaciones con la naturaleza es, como se ha dicho, un concepto fundador de la cosmovisión y la epistemología indígena. El concepto de sostenibilidad indígena se enfrenta y contrapone a las consecuencias de un desarrollismo asentado sobre la productividad natural, el utilitarismo de los recursos naturales, y la consideración colateral y externalizante de la biodiversidad. La propiedad privada de los recursos naturales no es una categoría central para poder entender la relación de los pueblos indígenas con la Naturaleza. Desde el Buen Vivir se quiebra la estricta relación existente en Occidente entre Economía y Naturaleza, transitándose a una consideración biocéntrica de la vida (individual-colectiva) como eje epistemológico del Buen Vivir. Es en este sentido que se puede hablar — con la Constitución ecuatoriana- de derechos de la naturaleza. La dimensión holística del conocimiento que el Buen Vivir implica supone sintetizar de manera interdependiente la tríada: ecología-espiritualidad-conocimiento. De ahí el carácter sacral de la Naturaleza en la epistemología del Buen Vivir; y de ahí la consideración cualitativamente novedosa que emerge desde el Buen Vivir, como el de Justicia ecológica. La potencia de lo Común se infiltra en esta consideración del Buen Vivir al establecer un necesario control colectivo-comunitario de cualquier forma de apropiación sobre la Naturaleza.

El binomio Buen Vivir-Naturaleza implica reorientar la base productiva de la vida desde una nueva metodología: el relacionismo metodológico ${ }^{60}$. Ello implica un redescubrimiento del territorio indígena en cuanto espacio de intercambio socio-cultural y político. Exige trascender una cosmovisión anclada en

58 WaLSH, C., Interculturalidad, Estado, sociedad. Luchas (de) coloniales de nuestra época, Universidad Andina Simón Bolivar, Abya Yala, Quito, 2009, pp. 62 y ss.

59 Martínez DE BRINGAS, A., "Derechos humanos y cooperación internacional para el desarrollo en América Latina. Crónica de una relación conflictiva», Cuadernos de Trabajo Hegoa, $\mathrm{n}^{\circ}$ 65, 2014, en red http://publicaciones.hegoa.ehu.es/assets/pdfs/327/Cuadernos Hegoa_n\%C2\%BA65.pdf?1421153634.

60 Para el relacionismo metodológico las realidades primeras son las relaciones sociales, siendo los individuos y las instituciones sociales, realidades segundas: especificaciones de la realidad social. No se trata de superar la tensión individual-colectiva en una síntesis superior, cualitativamente distinta. Sino en desplazar nuestra mirada sobre esta tensión. Esto es, en proponer otra manera de mirar y enfocar dicha relación. Cf. Corcuff, P., «Figuras de la individualidad: de Marx a las sociologías contemporáneas», en Las nuevas sociologías, Alianza, Madrid, 2005, pp. 12-13; GINER, S., «Intenciones humanas, estructuras sociales: para una lógica situacional» en CRUz, M., (coord.) Acción Humana, Barcelona, Ariel, 1997, pp. 78-94; Sociología, Barcelona, Península, 1988, pp. 39 y ss.; Reichmman, J., La habitación de Pascal. Ensayos para fundamentar éticas de suficiencia y políticas de autocontención, Madrid, Catarata, 2009, capítulos 9 y 10. 
una concepción tradicional del desarrollo caracterizado por la progresividad lineal en la manera de entender la implementación del desarrollo, y por el pensamiento dicotómico (desarrollado-subdesarrollado; rico-pobre). El dualismo ontológico propugnado por la Modernidad se ha venido construyendo sobre una tajante separación del individuo respecto de la comunidad y lo colectivo; sobre una comprensión del conocimiento objetivo y de la ciencia como únicos modelos válidos de conocer; sobre una construcción cultural de la "economía» drásticamente separada de las lógicas y procesos de la Naturaleza, en cuanto ámbito independiente y autónomo de la práctica social; sobre una consideración del mercado como una entidad auto-regulada, externa e independiente a las relaciones sociales. Frente a ello, esta nueva metodología propone, desde el Buen Vivir, una ontología relacional ${ }^{61}$, que evite la división entre naturaleza y cultura, entre individuo y comunidad, entre nosotros y ellos, y propugne la dimensión relacional de la realidad en varias dimensiones: ecológica, política, económica, cultural y espacial ${ }^{62}$. Desde ahí los derechos de la naturaleza se identifican con el derecho a la existencia en un sentido lato: como interconexión trasversal de todo lo vivo. Ello implica, de alguna manera, ponerse en el camino del decrecimiento, abandonando el modelo capitalista de desarrollo basado en el extractivismo, en la inserción sumisa al mercado y en la heterogeneidad estructural del aparato productivo.

El binomio Buen Vivir-Naturaleza establece un importante fundamento para lo Común al fijar, como corazón de su estructura, la importancia de la organización colectiva, social y política. Con ello se pone de manifiesto el carácter interdependiente, inescindible y dependiente de la diversidad biológica y cultural. Ambas diversidades son geográficamente coexistentes: la biodiversidad es condición de posibilidad de la diversidad cultural y viceversa. El Buen Vivir y lo Común comparten programa y proyecto al poner como centro de su sustentabilidad la reproducción social, la importancia del cuidado domésticocomunitario (enfermos, mayores, niños/as, etc.), los derechos de las mujeres, replanteando, de esta manera, el modelo organizacional de Estado. Desde este punto de vista la interculturalidad funciona como base y cimiento de lo Común: el conocimiento tradicional indígena.

Una cuarta idea fuerza vendría ensamblada por el binomio Buen Vivir-Globalización. Ello implica protección y responsabilidad última por lo Común. Reclama para su mantenimiento la colectivización de la reproducción social: se

61 La identidad relacional implica tener una idea de uno mismo en tanto que parte y componente necesario de una unidad mayor: la del grupo-comunidad. La identidad relacional implica, a su vez, la incapacidad para concebirse uno mismo como un componente extraño y ajeno de las relaciones en las que se inserta; la imposibilidad absoluta de concebir (se) fuera de las relaciones que intrínsecamente nos constituyen. Hernando, A., La fantasía de la individualidad. Sobre la construcción sociohistórica del sujeto moderno, Katz, Madrid, 2012, p. 67.

62 Escobar, A., «De la crítica al desarrollismo al pensamiento sobre la economía: pluriverso y pensamiento relacional» en COREGGIO y LAVILle (organizadores), op. cit., pp. 191-206; La invención del desarrollo, Universidad del Cauca, Popayán, 2012. 
trataría de dejar de buscar la vida en la reproducción del sufrimiento del otro. Exigencias perentorias para lo Común desde esta perspectiva serían: el cambio climático, las prácticas de consumo individual y colectivo, los límites biofísicos de la naturaleza, la desertificación, etc. Es necesario, por tanto, resaltar el carácter antinómico y contradictorio del Buen Vivir con el extractivismo, pese a las equivocadas pretensiones de convergencia y complementariedad de ambos procesos, como se está proponiendo en Ecuador.

Una quinta idea fuerza sería la relación del Buen Vivir con la emancipación y la transformación social. Desde ahí conceptos como productividad y competitividad deben ajustarse a las existencias del sistema, dando contenido a prácticas de economía solidaria empeñadas en revisar estilos de vida individuales y comunitarios. Proyectos tan ambiciosos como la redistribución de la riqueza, la Renta Básica ${ }^{63}$ y la distribución del ingreso constituirían una demanda central para el Buen Vivir indígena, siendo un insumo fundamental para la regeneración de lo Común. La propuesta de una nueva arquitectura financiera global sería la concreción más radical de un proyecto indígena de Buen Vivir.

\section{Aprendizajes desde la lógica de lo Común}

La lógica y el sentido último de lo Común nos arroja luz y experiencia para afrontar tres fallas importantes que se están produciendo en la globalización: en primer lugar, nos otorga claridad para afrontar falsas percepciones en la comprensión de la realidad; en segundo lugar, nos otorga sentido para entender ciertas inercias que se presentan como apodícticas e irremediables, pero que no son tales; en tercer lugar, abre espacios para ser conscientes y ponernos ante al límite de ciertas incertidumbres. La lógica y el sentido de estas fallas nos otorgan una experiencia importante para evidenciar el carácter nuclear de lo Común de cara a diseñar alternativas viables en la globalización. Sería la pretensión de construir una teoría crítica de lo Común.

La primera falla referida, en la que podemos descubrir y discernir aprendizajes, sería el ámbito de las falsas percepciones. Ésta se cimenta en una comprensión ilimitada e inagotable de los recursos y los bienes. Como consecuencia de este falso presupuesto actuamos a través de prácticas de desarrollo destructivo en las relaciones Norte-Sur, así como de una tendencia compulsiva al consumismo en cuanto actitud personal y social ante la vida. En el sustrato de la crítica a esta falta percepción estarían las teorías del postdesarrollismo y del decrecimiento ${ }^{64}$. El crecimiento exponencial y el consumo irredento que alimenta esta falsa percepción no permiten ver los problemas más urgentes, inmediatos e inmanejables que se abren en torno a la

63 Rentabasica.net; www.redrentabasica.org

64 Ver supra nota 45 y 54. 
tríada crisis ecología, crisis de producción social y crisis económica. Sin una cultura de la autocontención el desarrollismo acabará devorando a lo Común y, con ello, las condiciones de producción y reproducción de la vida en un sentido holístico.

Otra falsa percepción tiene que ver con la «paradoja del aislamiento» o «tiranía de las pequeñas decisiones», que impide ver el carácter común-colectivo de muchas construcciones individuales. El liberalismo individualista difumina cualquier pretensión de lo Común en la manera de entender y construir la globalización, los derechos, los procesos, siendo esta percepción falsa y desubicada. En conexión con ello estaría la implantación de fórmulas y soluciones técnicas a lo que son problemas estructurales de nuestra manera de vivir. La crisis ecológica no admite soluciones técnicas; sólo es posible afrontarla desde una cultura de la autocontención y auto-limitación. Eso pasaría por interpretar la energía, el crédito, los recursos naturales como un bien Común, lo que conllevaría la introducción de criterios democráticos en la lógica de la producción y el consumo.

Todas estas falsas percepciones vienen alimentadas, en su estructura, por una manipulación intencionada de la opinión pública orientada a mostrar una consideración de la Común y de la naturaleza como fuente inagotable e ilimitada, apercibiendo, a su vez, el carácter alarmista y desaforado de la crítica ecologista, feminista y de otros movimientos sociales. Esta manipulación reposa fundamentalmente en el arte de la explicación fragmentaria de las acciones y sus consecuencias, evitando una mirada sistémica y holística en el ámbito de las causas y efectos de la acción humana. Esto es, desacreditar la importancia de lo Común para afrontar los retos en el presente inmediato. Como expresa Reichmann «(...) cerca de los límites últimos del planeta es necesario tomar un punto de vista sistémico u holístico para comprender las dinámicas posibles y para actuar adecuadamente» ${ }^{65}$.

La segunda falla tiene que ver con el ámbito de las inercias. Para ello se parte de una constatación material: el hecho de que vivimos en un mundo social de profundas e inescindibles interdependencias, de tal manera que, cualquier inercia se convierte en estructural y afecta sistémicamente a la totalidad de la interdependencia. Esta inercia se implementa de manera todavía más agresiva si partimos de un conocimiento fundamentado en la falacia por «omisión de nexos», por disolución y desnaturalización de los múltiples vínculos que nos constituyen y soportan ${ }^{66}$. Este es el núcleo de la importancia de lo Común, de sus posibilidades y riesgos.

Esta primera inercia viene acompañada por otra de carácter mental y psicológica empeñada en la imposibilidad del cambio y en la irreversibilidad de lo real. Otro mundo no es posible y, desde ahí, la dimensión utópica de lo

65 Reichmman, J., Autoconstrucción, op. cit., p. 37.

66 Vega, L., La fauna de las falacias, Madrid, Trotta, 2013; Hubert Marraud, ¿Es lógic@? Análisis y evaluación de argumentos, Madrid, Cátedra, 2013. 
Común convierte su proyectos y sus propuestas en algo imposible. Esta inercia se apoya, a su vez, en la negación de lo Común como una realidad viviente, proponiéndola como una realidad contra-fáctica, utópica, más en el reino del deber-ser, que en el del ser. Pero cuando la huella ecológica de la humanidad supera la bio-capacidad de la tierra, esta inercia, que opera como una inversión sobre la importancia de lo Común, se vuelve ideológica. Desde aquí, la cultura de la autocontención no opera como un presupuesto de posibilidad, sino como la única vía admisible ante una realidad ya irreversible. Una teoría crítica de lo Común subyace como fundamento de esta propuesta.

Una tercera falla sería el ámbito de las incertidumbres. La principal es la de futuros abiertos a partir de las posibilidades que un pensamiento de lo Común genera anclado en la idea de responsabilidades estructurales y compartidas; así como la necesidad de una cultura de la contención y de la frugalidad política. Para ello es necesario desarrollar un pensamiento de la complejidad orientado al control de la naturaleza, lo socio-productivo y lo económico. Revisar el concepto de complejidad puesto que los avances técnicos nos pueden ayudar a simplificar el metabolismo físico con el entorno natural, sin abandonar la complejidad cultural que nos constituye ${ }^{67}$. Ser más complejos para implementar una cultura de la autocontención, poniendo las ventajas del progreso técnico al servicio de la sostenibilidad.

Una teoría crítica de lo Común reclama una comprensión holística de la crisis del capital global como hemos venido anticipando. Desde la lógica de los Común es posible aunar las tres dimensiones de la gramática del conflicto social-global e intentar diseñar propuestas no autónomas sino interdependientes desde esta comprensión de la crisis. Esas tres dimensiones, inescindibles e interdependientes son: la ecológica, la social-reproductiva y la económica. De alguna manera, hasta ahora, el pensamiento sobre lo Común trataba de dar salida sólo a algunas de esas dimensiones. Algunas de las propuestas sugeridas en este ensayo nos avalan para sugerir que ya no caben soluciones autónomas ni escindidas para la construcción de la justicia social ${ }^{68}$. Desde la lógica de lo Común es necesario dar salida, de manera trenzada, a esa triple e inescindible dimensión de la crisis de justicia social en la que vivimos. La ecológica, en modo de autocontención, en la medida en la que somos conscientes - tras las enseñanzas de Polanyi- de que la Naturaleza es condición indispensable, tanto para la vida social y sus vínculos, como para la producción de mercancías y la reproducción del capital. La social-reproductiva, que apunta a todo el rico espectro de las capacidades sociales, de las posibilidades emocionales, de la fuerza del vínculo en lo Común, pero que reclama poner en el centro de debate

67 Sempere, J., «¿Mejor con menos? Decrecimiento, austeridad y bienestar», ponencia en la Universidad de Valencia, manuscrito, 2014; MoRIn, E., Los siete saberes necesarios para la educación del futuro, Barcelona, Paidós, 2001, pp. 47 y ss.

68 Una perspectiva interesante en este sentido es FrASER, N., «Puede la sociedad transformarse en una commodity? Reflexiones pospolanyianas de la crisis capitalista», en CoRAGGIE Y Laville, Op. Cit., pp. 523-537. 
para su desarrollo y despliegue las prácticas de dominación que hoy caracteriza a nuestro sistema. La económica, en cuanto exigencia de una economía necesaria de mercado y de sus exigencias productivas, pero un mercado regulado desde las exigencias de derechos que impone lo Común.

Universidad de Deusto

Asier Martínez de Bringas

asier.martinez@deusto.es

[Artículo aprobado para publicación en diciembre de 2015] 